\title{
Estudio Morfológico de la Próstata y Glándulas Vesiculares de Cobayo (Cavia porcellus)
}

\author{
Morphologic Study of the Prostate and Vesicular Glands of the Guinea Pig (Cavia porcellus)
}

\author{
Bélgica Váquez \& Mariano del Sol
}

VÁSQUEZ, B. \& DEL SOL, M. Estudio morfológico de la próstata y glándulas vesiculares de Cobayo (Cavia porcellus). Int. J. Morphol., 28(4):1301-1307, 2010.

RESUMEN: El objetivo de esta investigación fue conocer la morfología de la próstata y glándula vesicular del cobayo (Cavia porcellus), describiéndose aspectos mesoscópicos, histológicos e histoquímicos. Se utilizaron 5 cobayos machos adultos (Cavia porcellus) sanos y alimentados con pellets, zanahorias y frutas ad libitum, en el Bioterio de la Universidad de La Frontera. Una vez sacrificados los animales, fueron aisladas las estructuras cuyos conductos terminaban en la uretra (conductos deferentes, glándulas vesiculares, glándulas coaguladoras, próstata y glándulas bulbouretrales). La próstata y las glándulas vesiculares fueron fijadas en formalina tamponada durante 24 horas y procesadas para su inclusión en paraplast. Se realizaron cortes seriados de $4 \mu \mathrm{m}$ de grosor, los cuales fueron teñidos para los estudios histológico e histoquímicos. El análisis se realizó a través de un microscopio Carl Zeiss, Axiolab, con cámara Cannon, G6. La próstata se encuentra dorsal a la uretra y está constituída por una masa de tejido glandular cubierto por una delgada cápsula de tejido fibroso y células musculares lisas. Presenta dos lóbulos, derecho e izquierdo, unidos por un istmo dorsal a la uretra, por la cara ventral de cada lóbulo emergen de 8 a 10 pequeños conductos excretores. Histológicamente, está compuesta por unidades túbulo-alveolares recubiertos por epitelio secretor simple cúbico. Las glándulas vesiculares son dos estructuras túbulo-lobulares. Se ubican dorsal a la uretra, relacionándose ventralmente con los conductos deferentes y la cara dorsal de la vejiga. Histológicamente, presentan una capa mucosa con un epitelio cilíndrico de tipo secretor; una capa media constituida principalmente por tejido muscular liso y una capa externa serosa. La histoquímica, en ambas glándulas fue negativa para glucógeno, mucinas neutras y ácidas, sulfatadas y no sulfatadas, tanto en el tejido glandular como en su producto de secreción. La próstata y glándulas vesiculares del cobayo, guardan relación con aspectos morfológicos de otros mamíferos. Sin embargo, las diferencias encontradas en los resultados histoquímicos, sugieren que estas glándulas podrían cumplir roles distintos en el proceso reproductivo.

PALABRAS CLAVE: Próstata; Glándula vesicular; Anatomía; Histología; Histoquímica; Cobayo.

\section{INTRODUCCIÓN}

Los roedores son ampliamente usados en laboratorios con fines de investigación, siendo el cobayo (Cavia porcellus) el animal de experimentación desde inicios del siglo XX, utilizado especialmente en numerosas investigaciones en las áreas biomédica, genética y reproductiva.

En la literatura se encuentra una variada descripción respecto al número, ubicación y características morfológicas de las glándulas anexas del sistema reproductor de roedores. Estas características varían de una especie a otra e incluso, diversos autores señalan diferencias dentro de una misma especie. Cooper \& Schiller (1975), describieron que el cobayo (Cavia porcellus) presentaba una próstata, una glándula coaguladora, dos glándulas bulbouretrales y dos vesículas seminales. Sin embargo, Schilling, 1984; Tambrallo \& Fish, 2000 y Martín et al., 2004 indicaron que las glándulas coaguladora, vesicular y bulbouretral se presentaban en par y que la próstata era un complejo glandular único.

Las glándulas anexas del sistema reproductor en mamíferos y, en particular, la próstata y la glándula vesicular, se caracterizan porque la función del órgano depende de diversos factores, tales como, estímulos androgénicos (Murakoshi et al., 1992; Pelletier, 2002 y Nishino et al., 2004), patologías existentes (Babinski et al., 2002), ausencia de alguna glándula (Queen et al., 1981) y factores am-

* Universidad Autónoma de Chile, Chile.

** Universidad de La Frontera, Chile. 
bientales, como lo son las variaciones estacionales que marcan periodos de actividad e inactividad de estas glándulas (Oróstegui et al., 2000; Cepeda et al., 1999, 2006).

Estos factores no solo se reflejan en las fluctuaciones en el volumen y composición química de la secreción prostática y seminal, también pueden producir cambios morfológicos relativos a las características del epitelio secretor, porcentaje de tejido conjuntivo y vascular, entre otros (Oróstegui et al.; Babinski et al. y Cepeda et al., 2006).

Por lo anterior, conocer las características mesoscópicas, histológicas e histoquímicas de la próstata y las glándulas vesiculares del cobayo (Cavia porcellus) toma relevancia para, posteriormente, realizar estudios estereológicos y experimentales que permitan comprender de mejor manera la fisiología de estas glándulas.

\section{MATERIAL Y MÉTODO}

Se utilizaron 5 cobayos machos adultos (Cavia porcellus), clínicamente sanos, mantenidos en cautiverio y alimentados con pellets comercial, zanahorias y frutas $\mathrm{ad}$ limitum, en el Bioterio de la Universidad de La Frontera, Chile.

Una vez sacrificados, se determinó su peso y talla cérvico caudal. Posteriormente, se disecó macro y mesoscópicamente la región pélvica, retirándose en bloque los componentes anatómicos del aparato urogenital. La disección se realizó utilizando una lupa ransor (10X). Luego, fueron aisladas las estructuras cuyos conductos terminaban en la uretra (conductos deferentes, glándulas vesiculares, glándulas coaguladoras, próstata y glándulas bulbouretrales). Se conservó la parte de la uretra donde se abrían los conductos de estas glándulas.

Se efectuó el estudio de la anatomía mesoscópica, describiéndose las relaciones existentes entre las glándulas. El tracto reproductivo fue mantenido húmedo con suero fisiológico estéril, mientras se realizaba la disección.

Las muestras fueron fijadas en formalina tamponada, durante 24 horas, y procesadas para su inclusión en paraplast Tissue Prepâ marca Fisher Scientific. Posteriormente, se realizaron cortes seriados de $4 \mu \mathrm{m}$ de grosor, los cuales fueron montados en portaobjetos. Los cortes de tejido desparafinados e hidratados, fueron teñidos siguiendo los métodos adecuados para su observación histológica e histoquímica. Para el análisis histológico, las secciones fue- ron teñidas con hematoxilina-eosina (H. E.) y tricómico de Masson. Para el análisis histoquímico se realizaron las técnicas de ácido periódico de Schiff (PAS), Azul Alcian (AA) (1\%) a pH 2.5, Azul Alcian (1\%) a pH 0.4. El montaje se realizó con Entellán (Merck). El estudio morfológico y las fotografías se realizaron utilizando un microscopio Carl Zeiss, Axiolab, con cámara Cannon, G6.

\section{RESULTADOS}

El peso promedio de los 5 cobayos fue de $711 \mathrm{~g}$ (D.E. $212,1)$ y la talla promedio cérvico-caudal fue de $25 \mathrm{~cm}$ (D.E. 2,0).

Las glándulas anexas del sistema reproductor de cobayo (Cavia porcellus) están compuestas por dos pequeñas glándulas bulbouretrales, una próstata, dos glándulas coaguladoras y dos glándulas vesiculares (Figs. 1A y 1B).
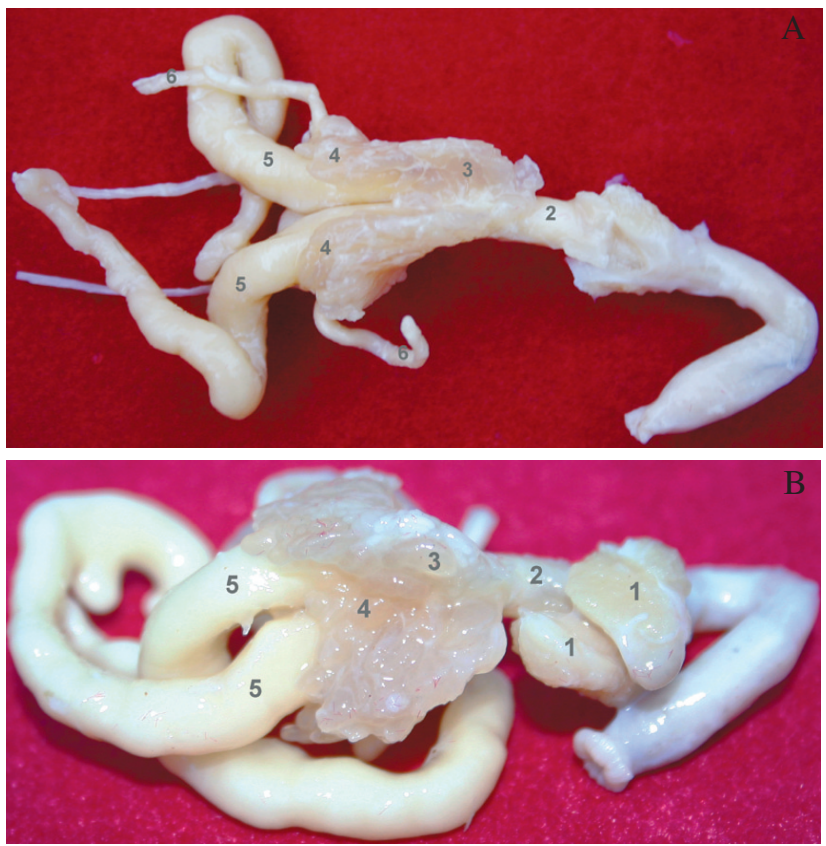

Fig. 1. Glándulas accesorias del aparato genital del cobayo macho (Cavia porcellus). 1. Glándulas bulbouretrales; 2. Uretra; 3. Próstata; 4. Glándulas coaguladoras; 5. Glándulas vesiculares; 6. Conductos deferentes.

La próstata de cobayo se encuentra ubicada dorsal a la uretra. Está constituida por una masa de tejido glandular cubierta por una delgada cápsula de tejido fibroso y células musculares lisas. Mide aproximadamente 20,25 mm (D.E. 3,80 ) de largo y $15,10 \mathrm{~mm}$ (D.E. 2,56 ) de ancho y pesa en promedio $0,9 \mathrm{~g}$ (D.E. 0,34 ). 


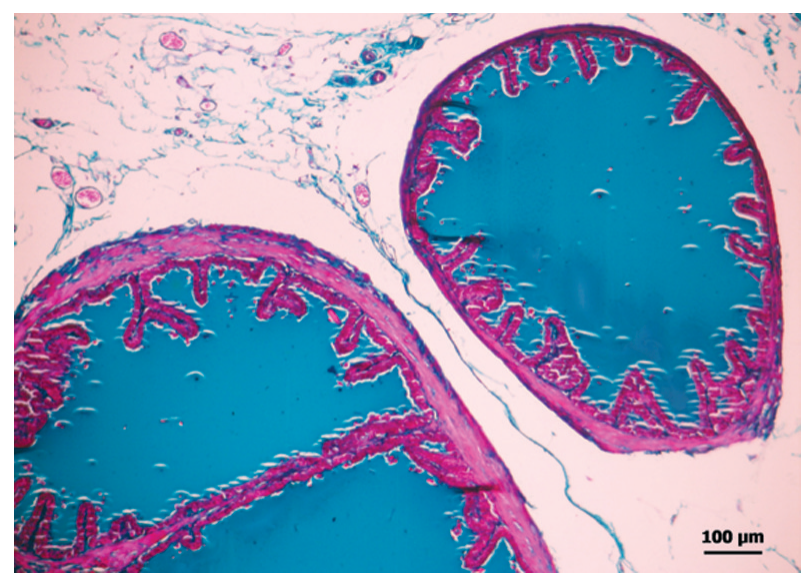

Fig. 2. Unidades secretoras túbulo-alveolares de la próstata de cobayo (Cavia porcellus), rodeadas por células musculares lisas y escaso tejido conectivo. Tricrómico de Masson (100X).

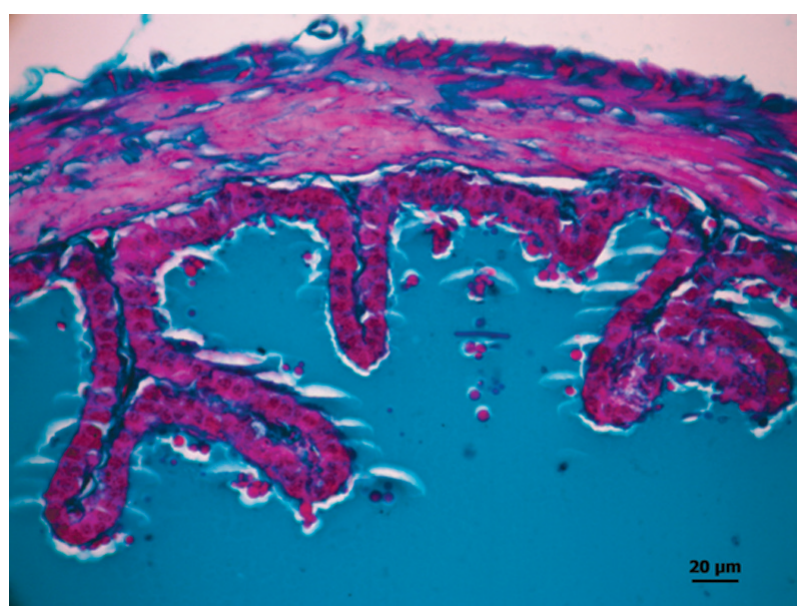

Fig. 3. Epitelio secretor simple cúbico de la glándula protática de cobayo (Cavia porcellus). Lámina propia poco abundante con fibras colágenas (verde) y capa media con abundantes células musculares lisas (rojo). Tricrómico de Masson (400X).

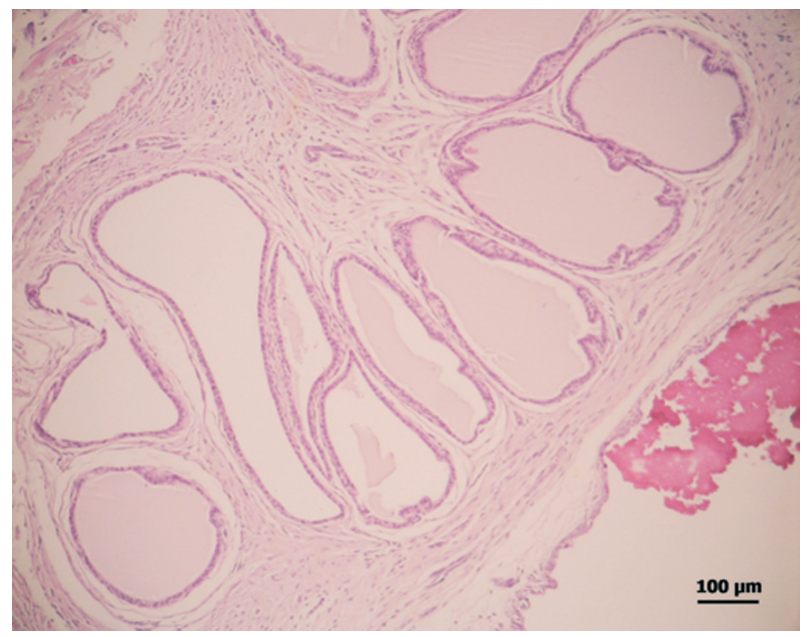

Fig. 4. Conductos excretores de la glándula prostática de cobayo. H.E. (100X).
Morfológicamente, la próstata presenta un surco poco profundo en la parte mediana de su cara dorsal que divide la glándula en dos lóbulos, derecho e izquierdo. Por la cara ventral de cada lóbulo emergen de 8 a 10 pequeños conductos excretores que se dirigen hacia la superficie dorsal y un tanto lateral de la uretra. Estos conductos desembocan caudalmente a los conductos excretores de las glándulas coaguladoras, vesiculares y los conductos deferentes. La próstata, se relaciona, principalmente, con la uretra y la glándula coaguladora a través de su cara ventral, las glándulas vesiculares y los conductos deferentes con la porción más craneal de la glándula y con la vejiga a través de los extremos libres de la cara ventral de cada lóbulo.

Histológicamente, la próstata está compuesta por numerosas unidades túbulo-alveolares redondeadas o poligonales, rodeadas por escaso tejido conjuntivo denso y abundantes fibras musculares lisas. El epitelio secretor se compone por células cúbicas en un solo estrato, cuyos núcleos redondos u ovales, ocupan una posición central. En aquellas zonas glandulares que contienen menor cantidad de secreción en el interior de la unidad glandular, se observan proyecciones digitiformes de mayor tamaño hacia la luz. Por debajo del epitelio existe una delgada lámina propia fibrosa (Figs. 2 y 3 ).

Se observó acumulación de secreción en el interior de la luz glandular, en todos los casos estudiados, sin concreciones o cuerpos amiláceos. El tejido estromal más alejado de las unidades glandulares se presentaba menos denso, con mayor cantidad de células adiposas y fibras colágenas en una disposición laxa.

Los conductos excretores de los lóbulos de la próstata, presentan un epitelio simple cúbico, observándose secreción en su interior (Fig. 4).

Los resultados obtenidos a través de los métodos histoquímicos, revelaron ausencia de glucógeno, mucinas neutras, ácidas sulfatadas y no sulfatadas para las células glandulares de la próstata y su producto de secreción. En los conductos excretores también se observó reacción negativa tanto para PAS, como para AA (1\%) pH 2,5 y 0,4.

Las glándulas vesiculares del cobayo, anatómicamente, son dos estructuras túbulo-lobulares que miden aproximadamente 102,60 mm (D.E. 21,71) de largo. Presentan un diámetro mayor de $5,57 \mathrm{~mm}$ (D.E. 1,04) y diámetro menor de 2,19 $\mathrm{mm}$ (D.E. 0,07$)$ y peso promedio de 1,5 g (D.E. 0,38 ).

Se localizan sobre la cara dorsal de la uretra, relacionándose ventralmente con los conductos deferentes y la cara dorsal de la vejiga. La porción más caudal de las glándulas vesiculares, están cubiertas por la cara ventral de las glándulas coaguladoras, haciendo difícil la visualización de los con- 
ductos excretores de cada glándula vesicular. Estos conductos desembocan un tanto craneal y medialmente a los conductos prostáticos y los de la glándula coaguladora y, levemente, caudal a los conductos deferentes en la uretra (Fig. 5).

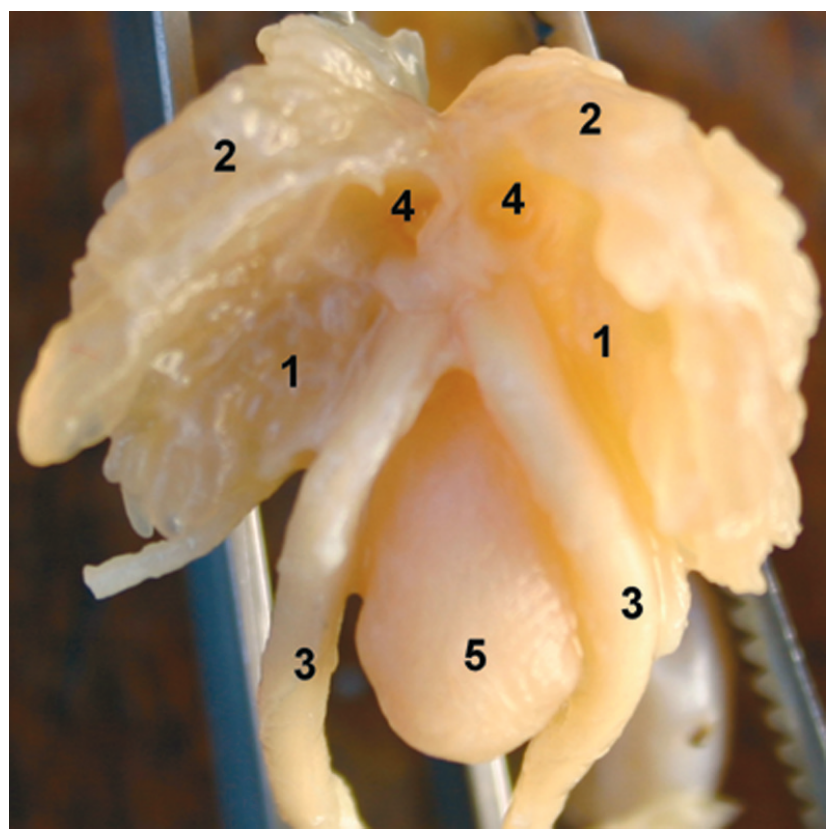

Fig. 5. Glándulas accesorias del aparato genital del cobayo macho (Cavia porcellus). 1. Próstata, cara ventral; 2. Glándula coaguladora, cara ventral; 3. Conductos deferentes; 4. Desembocadura de las glándulas vesiculares; 5 . Vejiga.

Histológicamente, las glándulas vesiculares presentan una capa mucosa, constituida por pliegues que se orientan hacia la luz de la glándula y una lámina propia poco abundante; una capa media constituida principalmente por tejido muscular liso de disposición plexiforme y fibras colágenas y una capa externa o serosa (Fig. 6).

La mucosa está revestida por un epitelio cilíndrico de tipo secretor, cuyas células presentan núcleos grandes y ovalados ubicados principalmente en el tercio basal de la célula, ocupando gran parte del citoplasma. La lámina propia está constituida por tejido conectivo laxo poco abundante (Fig. 7). Los conductos excretores de las vesículas seminales están revestidos por un epitelio que varía desde cilíndrico simple a transición, por su cercanía con la uretra.

La histoquímica resultó negativa para PAS y AA pH 2,5 y 0,4 tanto en las células glandulares como en su producto de secreción. Sin embargo, los conductos excretores de estas glándulas presentaron resultados positivos para glucógeno, mucinas neutras y ácidas, sulfatadas y no sulfatadas principalmente en la zona apical de estas células.

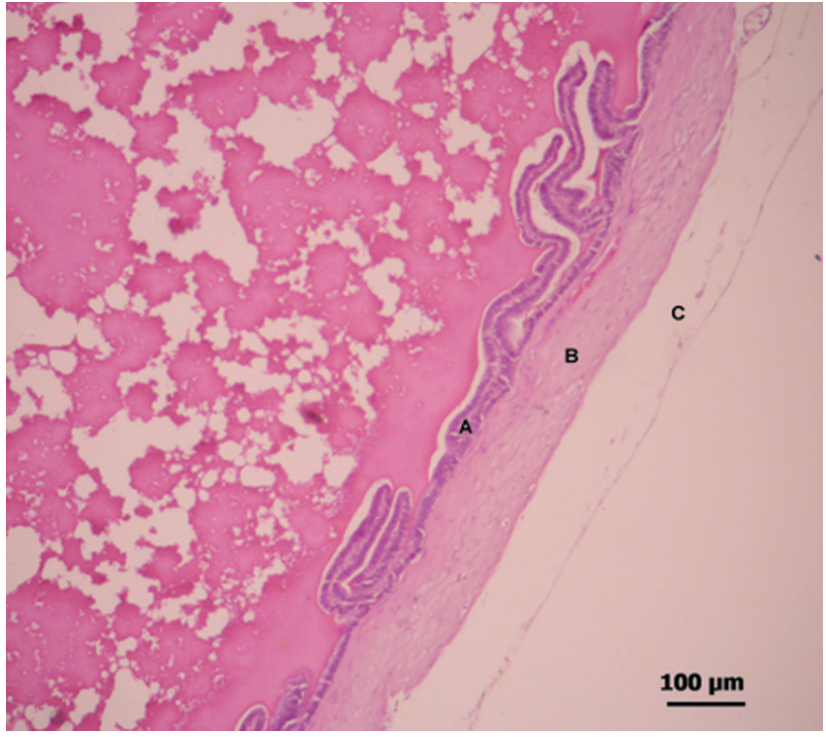

Fig. 6. Glándula vesicular de cobayo (Cavia porcellus). (A) capa mucosa, (B) capa muscular y (C) capa serosa. H. E. (100X).

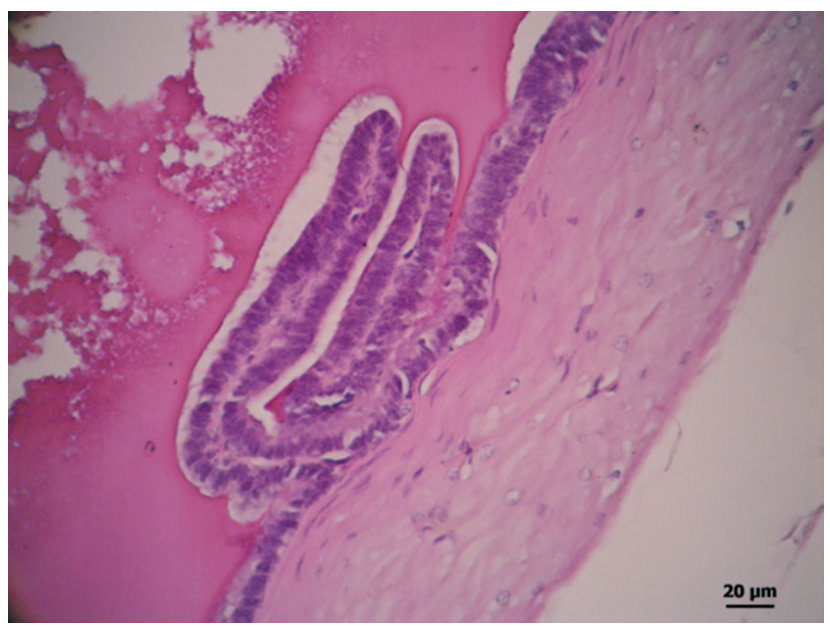

Fig. 7. Epitelio simple cilíndrico de la glándula vesicular de cobayo, lámina propia poco abundante. H. E. (100X).

\section{DISCUSIÓN}

A pesar de las variadas características morfológicas que presentan las glándulas anexas del sistema reproductor en mamíferos (Junqueira \& Martins, 1947; Mann, 1974; Holtz \& Foote, 1978; Gude et al., 1982; Vásquez \& del Sol, 2002; Moore \& Dalley, 2002; Snell, 2002 y Martín et al. (2004) la próstata es una glándula que siempre se encuentra presente (Dellmann, 1993).

En el cobayo, Cooper \& Schiller y Martín et al., señalaron que la próstata estaba constituida por dos pares de 
lóbulos, uno pequeño ventral a la uretra y otro grande dorsal, unidos por un istmo transverso. Zhao et al., 1993, describen sin embargo, que esta glándula, en el cobayo a los 35 días de gestación y 90 días después del parto, está compuesta por tres lóbulos, uno lateral, otro dorsal y la glándula coaguladora. En este estudio, la próstata de cobayo adulto estaba constituida por dos lóbulos, uno derecho y otro izquierdo, unidos por un istmo dorsal a la uretra. Sin embargo, la morfología macroscópica observada en la glándula vesicular en el cobayo, es semejante a la descrita por Cooper \& Schiller; Schilling y Martín et al.; es decir, constituidas por dos glándulas voluminosas túbulo-lobulares que terminan en punta, ubicadas dorsal a la uretra. Estas descripciones concuerdan también con lo observado en rata y hamster (Junqueira \& Martins; Gude et al.; Olds \& Olds, 1979; Jesik et al., 1982 y Popesko et al., 1992).

Histológicamente, la próstata está constituida por unidades túbulos-alveolares, cuyo epitelio secretor se compone por células cúbicas en un solo estrato, rodeadas por escaso tejido conjuntivo y abundantes fibras musculares lisas y entre cada unidad glandular se observa tejido conectivo laxo. Similares descripciones fueron realizadas en cobayo por Cordeiro et al., 2004 y en rata por Junqueira \& Martins; Gude et al.

En general, las características histológicas de las glándulas vesiculares del cobayo son similares a las descritas en otros roedores como ratas (Junqueira \& Martins; Gude et al.) y Chinchilla laniger (Oróstegui et al.); pudiéndose visualizar tres capas bien definidas, una mucosa con un epitelio cilíndrico de tipo secretor, una media y otra serosa.

El hecho que el cobayo y la rata sean roedores que presentan un ciclo estral poliéstrico no estacional, sus ciclos no dependen de factores como el fotoperíodo. Este hecho, marca una diferencia con lo observado en próstata y vesícula seminal de Chinchilla laniger, ya que estas glándulas experimentan cambios microscópicos y macroscópicos a través del año, observándose una máxima actividad en el periodo otoño-invierno (Oróstegui et al.; Cepeda et al., 2006).

Por otro lado, la edad es un factor importante a considerar. Estas descripciones fueron realizadas en cobayos adultos, encontrándose en un periodo reproductivo activo. Horsfall et al. 1994, señalaron que la próstata de cobayo durante el envejecimiento sufre un aumento de la masa del estroma, fibrosis estromal significativa y prostatitis ocasional. Estos autores plantean que existe una similitud en algunas de las características del estroma del músculo liso prostático, entre hombres de edad avanzada y los cobayos, sugiriendo que puede haber procesos fisiopatológicos comunes.
Es importante considerar la dependencia que presentan estas glándulas a los estímulos androgénicos y antiandrogénicos, los cuales pueden causar modificaciones sobre las características morfológicas descritas en la próstata y glándula vesicular de cobayo. Así, Cordeiro et al., en un estudio realizado en la próstata lateral de cobayo de diferentes edades, evaluaron los cambios morfológicos y ultraestructurales en el tejido glandular después del tratamiento con flutamida, señalando que este fármaco promueve variaciones en la distribución y concentración del componente celular de esta glándula. Anteriormente, Tilley et al. 1989, demostraron a través de inmunocitoquímica, la presencia de receptores androgénicos en el estroma prostático del cobayo, sugiriendo que tanto los estrógenos como andrógenos son necesarios para el normal desarrollo de esta glándula.

Una característica de la actividad secretora de las glándulas anexas del sistema reproductor en mamíferos es que, en muchos casos, los órganos que en un tiempo se creía ser homólogos por su anatomía, difieren notablemente en la naturaleza química de sus productos de secreción. Esto es especialmente correcto con las secreciones de la próstata y vesícula seminal. Por ejemplo, la próstata del hombre secreta sustancias tales como: fosfatasa ácida y ácido cítrico (Gartner \& Hiatt, 2002 y Geneser, 2003); sin embargo la secreción de la glándula vesicular de búfalo también presenta ácido cítrico y además fructuosa (Eissa, 1980).

Los resultados histoquímicos revelaron ausencia de glucógeno, mucinas neutras, ácidas sulfatadas y no sulfatadas para las células glandulares y su producto de secreción, tanto en la próstata como en las glándulas vesiculares de cobayo. Sí se observó reacción positivas para estas sustancias en los conductos excretores de la glándula vesicular. Para Moussa et al. (1983), las glándulas vesicularer del búfalo no muestran relación significativa con los métodos de PAS y AA. Las glándulas vesiculares no presentan células mucosas ni serosas. Vásquez \& del Sol, observaron en la próstata del conejo (Oryctolagus cuniculus) mucinas neutras y ácidas en las células secretoras y su producto de secreción. Además, encontraron que la distribución de estas mucinas en los acinos glandulares era variable, es decir, existían zonas intensamente teñidas y zonas teñidas en menor intensidad e incluso, sin teñir.

La morfología y fisiología de la próstata y glándulas vesiculares son distintas entre mamíferos. Sus características mesoscópicas, histológicas e histoquímicas, se pueden ver influenciadas por distintos factores. Así, conocer los aspectos morfológicos de estas glándulas, puede ser fundamental para comprender los fenómenos asociados a su fisiología. Estos resultados permitirán fundar las bases para futuros estudios morfológicos y estereológicos en las glándulas anexas del sistema reproductor del cobayo (Cavia porcellus). 
VÁSQUEZ, B. \& DEL SOL, M. Morphological study of the prostate and vesicular glands of the guinea pig (Cavia porcellus). Int. J. Morphol., 28(4):1301-1307, 2010.

SUMMARY: The objective of this investigation was to study the morphology of the prostate and vesicular gland of the guinea pig (Cavia porcellus), describing the mesoscopic, histological and histochemical aspects. Five healthy adult male guinea pigs (Cavia porcellus) were used. The animals received pellets, carrots and fruit ad libitum in the Biotherium of the Universidad de La Frontera. Once the animals were sacrificed the structures which ducts ended in the urethra, (vas deferens, vesicular glands, coagulator glands, prostate and bulbourethral glands) were isolated. The prostate and vesicular gland were fixed in buffered formalin during 24 hours and processed for their inclusion in paraplast. Serial cuts $4 \mu \mathrm{m}$ thick were realized and stained for histological and histochemical studies, using a Carl Zeiss, Axiolab microscope with a Cannon G6 camera. The prostate is located dorsal to the urethra and is constituted by a mass of glandular tissue covered by a thin capsule of fibrous tissue and smooth muscular cells presenting two lobes, right and left joined to the urethra by a dorsal isthmus. Emerging through the ventral surface of each lobe are 8 to 10 small excretory ducts. Histologically it is composed by alveolar tubular units covered by a simple cubical secretor epithelium. The vesicular glands are two tubular lobular structures located dorsal to the urethra and are connected ventrally with the vas deferens and the dorsal surface of the bladder. Histologically presenting a mucous layer with a secretor type cylindrical epithelium, a medium layer namely constituted by smooth muscular tissue and a serous external layer. Histochemical reaction in both glands was negative for glycogen, for neutral and acid mucins, both sulfate and non sulfate, in the glandular tissue as well as the secretor product. The prostate and vesicular glands of the guinea pig are related to morphological aspects of other mammals. However, the differences found in the histochemical results suggest that these glands could have different effects in the reproductive process.

KEY WORDS: Prostate; Vesicular gland; Anatomy; Histology; Histochemistry; Guinea pig.

\section{REFERENCIAS BIBLIOGRÁFICAS}

Babinski, M.; Chagas, M.; Costa, W. \& Pereira, M. Morfología y fracción del área del lumen glandular de la zona de transición en la próstata humana. Rev. Chil. Anat., 20(3): 255-62, 2002.

Cepeda, R.; Adaro, L.; Peñailillo, P. \& Oróstegui, C. Variaciones morfológicas estacionales de las glándulas bulbouretrales de la chinchilla (Chinchilla laniger, GREY), en cautiverio. Rev. Chil. Anat., 17:(1)59-66, 1999.

Cepeda, C. R.; Adaro, A. L. \& Peñailillo, G. P. Variaciones morfométricas de la próstata de Chinchilla laniger (Molina, 1982) y de la concentración de testosterona plasmática durante un ciclo reproductivo anual. Int. J. Morphol., 24(1):89-97, 2006.

Cooper, G. \& Schiller, A. L. Anatomy of the Guinea pig. Harvard University Press, Cambridge, 1975. p. 417.

Cordeiro, R. S.; Scarano, W. R.; Góes, R. M \& Taboga, S. $\mathrm{R}$. Tissue alterations in the Guinea pig lateral prostate following antiandrogen flutamide therapy. Biocell. 28(1): 21-30, 2004.

Dellmann, V. Histología Veterinaria. 2a ed. Acribia, Zaragoza, 1993. pp 257-60.
Eissa, H. M. A. Seasonal biological activity of the accessory genital glands of buffalo-bulls. Thesis, Fac. Vet. Med., Cairo, 1980.

Gartner, L. P. \& Hiatt, J. L. Texto atlas de histología. 2a ${ }^{\text {a }}$ ed. México, McGraw-Hill, 2002. pp 478-80.

Geneser, F. Histologia com bases biomoleculares. 3a. ed. Rio de Janeiro, McGraw-Hill, 2003. pp 520-2.

Gude, W. D.; Cosgrove, G. E. \& Hirsch, G. P. Histological atlas of the laboratory mouse. New York, Plenum Press, 1982. p. 16-79.

Holtz,W.; Foote, H. The anatomy of the reproductive system in male dutch rabbits (Oryctolagus cuniculus) with special emphasis on the accessory sex glands. $J$. Morphol., 156:1-12, 1978.

Horsfall, D. J.; Mayne, K.; Ricciardelli, C.; Rao, M.; Skinner, J. M.; Henderson, D. W.; Marshall, V. R. \& Tilley, W. D. Age-related changes in guinea pig prostatic stroma. Lab Invest.,70(5):753-63. 1994.

Jesik, C. J.; Holland, J. M. \& Lee, C. An anatomic and histologic study of the rat próstate. The Prostate, 3(1): 81-97, 1982. 
Junqueira, L. C. U. \& Martins, E. O. Atlas de anatomía microscópica do rato. São Paulo, Universidade de São Paulo - USP, 1947. pp. 62-73.

Mann, T. Secretory function of the prostate, seminal vesicle and other male accessory organs of reproductio. $J$. Reprod. Fert., 37:179-88, 1974.

Martín, R; Martín, P \& Gonzáles, J. Atlas de anatomía de animales exóticos. Barcelona, España, 2004.

Moore, K. L. \& Dalley, A. F. Anatomía con orientación clínica. 4a. ed. Buenos Aires, Panamericana, 2002.

Moussa, M.; Badawy, A.; Kandil, M. \& Shahin, Y. Histological and histochemical studies of the accesory genital glands of buffalo-bull (Bubalis bubalis). Anat. Anz., 153:429-39, 1983.

Murakoshi, M.; Tagawa, M.; Inada, R. \& Suzuki, M. Effects of testosterone, and testosterone plus estrogen, in the castrated rat ventral prostate histopathological and immunocytochemical studies. Tokai J. Exp. Clin. Med., 17(3-4):133-7. 1992.

Nishino, T.; Wedel, T.; Schmitt, O.; Biihlmeyer, K.; Schönfelder, M.; Hirtreiter, C.; Schulz, T.; Kiihnel, W. \& Michna, H. Androgen-dependent morphology of prostates and seminal vesicles in the Hershberger Assay: Evaluation of immunohistochemical and morphometric parameters. Ann. Anat., 186:247-53, 2004.

Olds, R. J. \& Olds, J. R. A colour atlas of the rat. Dissection guide. London, Wolf Medical, 1979. p. 54-61.

Oróstegui, C.; Parraguez, V.; Adaro, L.; Peñailillo, P. \& Cepeda; R. Cambios histológicos y morfométricos de las vesículas seminales, inducidos por variaciones estacionales, en la Chinchilla laniger (GREY) en cautiverio. Rev. Chil. Anat., 18(1):89-96, 2000.

Pelletier, G. Effects of estradiol on prostate epithelial cells in the castrated rat. J. Histochemistry \& Cytochemistry., 50(11):1517-23, 2002.

Popesko, P.; Rajtová, V. \& Horák, J. A. A colour atlas of the anatomy of small laboratory animals. Bratislava,Wolfe, 1992. V. I. pp. 121-222.

Queen, K.; Dhabuwala, C. \& Pierrepoint, C. The effect of the removal of the various accessory sex glands on the fertility of male rats. J. Reprod. Fert., 62:423-6, 1981.
Schilling. P. Temas seleccionados sobre medicina de animales de laboratorio. El cobayo. Centro panamericano de fiebre aftosa. Serie de monografías científicas y técnicas. Rio de Janeriro, Brasil, No 13, 1984.

Snell, R. S. Anatomía clínica para estudiantes de Medicina. 6a. ed. México, McGraw-Hill, 2002. pp. 341-3.

Tambrallo, L. J. \& Fish, R. E. Laboratory animal medicine and science, series II Guinea pigs: biology and use in research. Produced by the Health Sciences Center for Educational Resources University of Washington Seattle WA 98195 , 2000. V-9023.

Tilley, W. D.; Horsfall, D. J.; Skinner, J. M.; Henderson, D. W. \& Marshall, V. R. Effect of pubertal development on estrogen receptor levels and stromal morphology in the Guinea pig prostate. Prostate. 15(2):195-210, 1989.

Vásquez, B. \& del Sol, M. Complejo prostático en el conejo (Oryctolagus cuniculus). Rev. Chil. Anat., 20(2):175-80, 2002.

Zhao, C. Y; Tam, C. C. \& Wong, Y. C. Morphogenesis and ductal development of the prostatic complex of the Guinea pig. J. Morphol., 217(2):219-27, 1993.

Dirección para correspondencia:

Prof. Bélgica Vásquez Pastene

Universidad Autónoma de Chile

Temuco

CHILE

Email:belgica.vasquez@uautonoma.cl

Recibido : 16-06-2010

Aceptado: 21-09-2010 
